\title{
A contrarreforma do Ensino Médio e as perdas de direitos sociais no Brasil`
}

The High School counter-reform and the loss of social rights in Brazil

\section{La contra reforma de la escuela secundaria y la pérdida de derechos sociales en Brasil}

\author{
Adriana Maria Cancella Duarte ${ }^{2}$ \\ Universidade Federal de Minas Gerais, Departamento de Administração Escolar da \\ Faculdade de Educação, Professora titular. \\ https://orcid.org/0000-002-7200-5703

\section{Juliana Batista dos Reis ${ }^{3}$} \\ Universidade Federal de Minas Gerais, Departamento de Administração Escolar da \\ Faculdade de Educação, Professora adjunta. \\ https://orcid.org/0000-0002-6477-5388
}

\section{Licinia Maria Correa ${ }^{4}$}

Universidade Federal de Minas Gerais, Departamento de Ciências Aplicadas à Educação, Professora associada.

https://orcid.org/0000-0003-0662-7229

\section{Shirlei Rezende Sales 5}

Universidade Federal de Minas Gerais, Programa de Pós-Graduação da Faculdade de Educação, Professora.

http://orcid.org/0000-0003-4446-9508

Resumo: 0 artigo busca identificar, descrever e analisar os processos e os efeitos da contrarreforma do Ensino Médio, regulamentada pela Lei $\mathrm{n}$. 13.415/17, e a consequente perda de direitos sociais, especialmente para a juventude brasileira. 0 Ensino Médio no Brasil, última etapa da educação básica, tem sofrido frequentes reformas nas últimas duas décadas, propostas pelos governos nacionais ou por iniciativa dos próprios estados federativos. A partir da apreciação da Lei n. 13.415/17, privilegia-se,

Este trabalho contou com apoio da Coordenação de Aperfeiçoamento de Pessoal de Nivel Superior - Brasil (CAPES) - código de Financiamento: 001 e com apoio da Fundação de Amparo à Pesquisa do Estado de Minas Gerais (Fapemig).

2 Doutora em Educação pela Universidade Federal de Minas Gerais; Mestrado em Serviço Social pela Pontificia Universidade Católica de São Paulo.

3 Doutora em Educação pela Universidade Federal de Minas Gerais; Mestre em Ciências Sociais pela Universidade Federal de São Carlos.

4 Pós-doutora em Sociologia pela Università degli Studi di Pádova-Itália; Doutora em Educação Escolar pela Universidade Estadual Paulista Júlio de Mesquita.

5 Doutora em Educação pela Universidade Federal de Minas Gerais; pós-doutoranda pela University of lllinois, USA. 
em um primeiro momento, a análise sobre os efeitos da contrarreforma para os sujeitos da escola (jovens estudantes e corpo docente). Em seguida, examina-se a proposta de organização curricular e a Base Nacional Curricular Comum para o Ensino Médio. Argumenta-se que a proposta de flexibilização reduz a educação básica à preparação para o mercado de trabalho, restringe e abrevia a oferta, amplia as desigualdades educacionais e oferece base legal para a privatização do ensino público. Conclui-se que a contrarreforma se configura como golpe à educação brasileira, pois não considerou o quadro geral do Ensino Médio atual (as condições de trabalho das(os) docentes e a infraestrutura existente hoje nas escolas), os avanços e orientações contidos no Plano Nacional de Educação (20142024), as experiências e os saberes dos sujeitos da escola e as pesquisas já desenvolvidas na área. 0 uso do conceito de contrarreforma potencializa a análise dos processos regressivos aos avanços dos direitos sociais diante dessa iniciativa.

Palavras-chave: Ensino Médio. Contrarreforma. Juventude. Currículo. Desigualdades escolares.

Abstract: This article seeks to identify, describe and analyze the processes and effects of the High School counter-reform, regulated by the law 13.415/17, and its loss of social rights, especially for the Brazilian youth. The High School in Brazil, last level of compulsory education, has suffered many reforms proposed by the Federal or states governments in the last two decades. By studying the law 13.415/17, in this article we initially focused on the analysis of the counter-reform effects on the school subjects. After that, we examined the curricular structure proposal and the National Curriculum Common Core for the High School. The argument is that the flexibility proposed in the curriculum simplifies the purpose of the compulsory education to the preparation for the labor market, restricts and reduces the offer, increases the educational inequalities and can justify legally the public schools privatization. The conclusion is that the counter-reform represents a coup against the Brazilian education, because it doesn't consider the characteristics of the current High School lthe teacher's labor conditions and the infrastructure of the schools), the achievements and orientations in the Educational National Plan (2014 - 2024), the subjects' experiences and knowledge and the researches that had been developed about the theme. The use of the concept "counter-reform" strengthens the analysis of the regressive processes regarding social rights when considering this initiative.

Keywords: High School. Counter-reform. Youth. Curriculum. School inequalities.

Resumen: El artículo busca identificar, describir y analizar los procesos y efectos de la contra reforma de la escuela secundaria, regulada por la Ley N¹3.415 / 17, y la consiguiente pérdida de derechos sociales, especialmente para juventud brasileña. La escuela secundaria en Brasil, la última etapa de la educación básica, ha sufrido reformas frecuentes en las últimas dos décadas, propuestas por los gobiernos nacionales o por iniciativa de los propios estados federativos. Desde la apreciación de la Ley 13.415 / 17, se privilegia, en un primer momento, el análisis sobre los efectos de la contra reforma lós sujetos de la escuela (jóvenes estudiantes y profesores). Luego, examinamos la organización curricular propuesta y la Base Curricular Nacional Común para la escuela secundaria. Se argumenta que la propuesta de flexibilización reduce la educación básica a la preparación para el mercado laboral, 
restringe y acorta la oferta, amplía las desigualdades educativas y proporciona una base legal para la privatización de la educación pública. Se concluye que la contrarreforma es un duro golpe para la educación brasileña, porque no consideró la realidad de la actual escuela secundaria llas condiciones de trabajo de los docentes y la infraestructura existente en las escuelas de hoyl, los avances y orientaciones contenidos en el Plan Nacional. Educación (2014-2024), las experiencias y conocimientos de los sujetos y las investigaciones ya realizadas. El uso del concepto de contra reforma contribuye al análisis de los procesos regresivos para el avance de los derechos sociales frente a esta iniciativa. Palabras llave: Escuela secundaria. Contrarreforma. Juventud. Curriculum. Desigualdades escolares.

Recebido em 3 de setembro de 2019 Aceito em 14 de abril de 2020 Publicado em 04 de junho de 2020

\section{APRESENTAÇÃO}

0 presente artigo busca discutir a contrarreforma do Ensino Médio apresentada em 2016 ao Congresso Nacional, pelo Governo de Michel Temer, logo após a sua posse como Presidente da República, ou seja, depois da aprovação do impeachment da presidenta Dilma Rousseff no Senado Federal. 0 grupo que se aliou a Temer para que ele chegasse à presidência apresentava um projeto de governo classista e autoritário (POCHMANN, 2017), que tinha como base o programa Uma Ponte para o Futuro, lançado pelo Partido do Movimento Democrático Brasileiro (PMDB) em outubro de 2015.

Esse programa, em síntese, propunha a austeridade fiscal; o orçamento impositivo; a revisão das vinculações constitucionais, como as existentes na saúde e na educação; as privatizações; a retração do investimento público em programas sociais; as reformas trabalhista e previdenciária; a eliminação de qualquer indexador de benefícios sociais ao salário mínimo, entre outros aspectos (PARTIDO DO MOVIMENTO DEMOCRÁTICO BRASILEIRO, 2015). Ou seja, um programa ultraliberal lançado, segundo seus(as) formuladores(as), em nome do equilíbrio das contas públicas e da retomada do crescimento econômico e para fomentar uma maior competitividade do País ante a economia global.

Algumas dessas propostas foram concretizadas nos dois anos de Governo Temer (2016-2018), como o congelamento do orçamento público por 20 anos, o que inviabiliza diretamente a implementação do Plano Nacional de Educação (PNE) (2014-2024); a reforma trabalhista; o encaminhamento da reforma previdenciária para ○ Congresso Nacional; a privatização de bens públicos, como o direito de exploração do pré-sal, a concessão de aeroportos, terminais portuários e ferroviários e as linhas de concessão de energia. 
Foi nessa conjuntura regressiva que a Medida Provisória (MP) n' 746, de setembro de 2016, foi encaminhada ao Congresso Nacional, contendo o que chamamos de contrarreforma do Ensino Médio (BRASIL, 2016b). Foi o primeiro ato do Governo Temer relativo especificamente à área da educação e ocorreu sem nenhum debate com as(os) professoras(es), estudantes, famílias, pesquisadoras(es) da área, especialistas ou movimentos sociais da educação. De acordo com Peroni (2017, p. 422),

\begin{abstract}
Quando políticas no nível nacional são gestadas retirando a participação, diálogo e autonomia da comunidade educacional, introduzidas de forma arbitrária, como é o caso da MP do ensino médio, e sem levar em consideração as construções já realizadas sobre os temas, temos a clara dimensão de qual projeto o capital quer para o país. Ademais, esses sujeitos encontram apoio naqueles que acreditam que suas ideias irão funcionar, ter impacto e gerar retorno como resultado social ou lucro.
\end{abstract}

Cabe registrar, de início, que a Exposição de Motivos que acompanhou a MP n. 746/2016 (BRASIL, 2016b) afirmava que a proposta de reforma do Ensino Médio estava alinhada com as premissas do Banco Mundial e do Fundo das Nações Unidas para a Infância (UNICEF). São também condizentes com as recomendações da Unesco (2003) e da OCDE (2009) para o Ensino Médio. No Brasil, essas propostas foram incorporadas pelo empresariado, organizado no movimento Todos Pela Educação (TPE) e seus parceiros, que congregam os maiores empresários brasileiros. ${ }^{6}$ Segundo Peroni (2017), esse grupo tem como objetivo claro pesar decisivamente na correlação de forças em nossa sociedade, impondo seu projeto hegemônico de sociedade e de educação.

A aprovação da contrarreforma do Ensino Médio ocorreu em fevereiro de 2017, quando foi promulgada a Lei n. 13.415. Adotamos neste artigo, desde o seu título, a terminologia contrarreforma para demarcar a nossa posição de considerá-la como uma forma de regressão dos direitos sociais da juventude brasileira. Argumentamos que ela quebra o conceito de educação básica construído na LDBEN/1996, reduz a educação a um aprendizado instrumental voltado a atender às mudanças do capitalismo contemporâneo, à flexibilização do mercado de trabalho e às demandas do empresariado, desconsiderando os saberes docentes e os anseios das(os) jovens brasileiras(os) por uma educação de qualidade, em diálogo com seus interesses e necessidades.

0 objetivo aqui, portanto, é apresentar a configuração da contrarreforma do Ensino Médio, dando maior destaque à análise dos aspectos relativos às demandas da juventude e a negação delas por meio da construção curricular. Para isso, utilizamos o 
estudo documental e bibliográfico, além de relatórios estatísticos disponíveis nos sites do Instituto Nacional Anísio Teixeira (INEP), do Instituto Brasileiro de Geografia e Estatística (IBGE) e do Tribunal de Contas da União (TCU).

0 texto está organizado em três seções, além desta apresentação inicial e das considerações finais. A primeira seção apresenta um quadro geral do Ensino Médio na ocasião da reforma, uma discussão acerca das mudanças processadas nessa etapa da educação a partir da Lei n. 13.415/2017 e suas principais implicações. A segunda problematiza a ausência dos sujeitos da escola na participação das proposições que alteraram significativamente o Ensino Médio. A última seção examina a proposta de organização curricular e a Base Nacional Curricular Comum para o Ensino Médio.

\section{AS CONFIGURAÇÕES DA CONTRARREFORMA DO ENSINO MÉDIO: LEI N. 13.415/2017}

0 Ensino Médio, última etapa da educação básica, foi estruturado na Constituição Federal de 1988 (BRASIL, 1988) e regulamentado pela Lei de Diretrizes e Bases da Educação Nacional (LDBEN) - Lei n. 9.394/1996 (BRASIL, 1996). Nesse aparato legal, o Ensino Médio foi configurado com a duração de três anos, responsabilizando-se por três funções clássicas: a propedêutica, a profissionalizante e a formativa (CURY, 2002).

0 conceito de educação básica foi construído no texto da LDBEN (1996), sugerindo a ideia de alicerce e de marcha progressiva (CURY, 1997), por meio da continuidade das etapas da Educação Infantil, do Ensino Fundamental e do Ensino Médio. Segundo Cury (1997, p. १14-115), o termo alicerce é empregado como "escolarização obrigatória", e marcha, como "luta contra a interrupção do mesmo processo, atendendo assim idealmente à concepção de pleno desenvolvimento da pessoa do educando." A LDBEN/1996 previu, ainda, que a etapa do Ensino Médio deve promover "o aprimoramento do educando como pessoa humana, incluindo a formação ética e o desenvolvimento da autonomia intelectual e pensamento crítico." (BRASIL, 1996, Art. 35, Inciso III).

Essa etapa da educação tem estado em foco nas últimas décadas, marcando presença no debate acadêmico e da sociedade em geral, considerando as reformas e contrarreformas que vem sofrendo desde a segunda metade da década de 1990. Nesse período, pode-se observar várias alterações em seus estatutos legais, como: expansão no número de matrículas (embora sem alcançar a almejada universalização); o seu caráter de finalização da educação básica e as poucas possibilidades de um grande contingente de jovens ter acesso à educação superior; a expansão da obrigatoriedade para os estudantes 
de 15 aos 17 anos, entre várias outras alterações. Ou seja, o Ensino Médio está imerso em tensões e contradições geradas por mudanças históricas que têm questionado seus objetivos, sua identidade e sua contribuição social (KRAWCZYK; FERRETTI, 2017).

Em 2017, quando a contrarreforma de que estamos tratando foi aprovada, o número de matrículas na educação básica no Brasil era de 48,6 milhões de estudantes e 184,1 mil escolas. Dessas matrículas, 7,9 milhões estavam no Ensino Médio (16,7\%), distribuídas em 28,5 mil escolas públicas e privadas. As redes estaduais respondiam por $84,8 \%$ dessas matrículas, considerando que, constitucionalmente, os estados federativos são os responsáveis diretos por essa etapa da educação básica; as instituições privadas, por १२,२\%; as escolas federais, por 2,4\%; e as municipais, por 0,6\% (MINISTÉRIO DA EDUCAÇÃO, 2017b).

De acordo com a Pesquisa Nacional por Amostra de Domicílios (PNAD) (IBGE, 2016a), a população de jovens de 15 a 17 anos no Brasil era de 10.637.610, e a taxa de escolarização era de $85 \%$. Entre essas(es) jovens, 1.593 .141 estavam fora da escola, 1.863.158 encontravamse ainda no Ensino Fundamental, e 83.663 eram analfabetaslos) (IBGE, 2016a). Há que se lembrar que desde 2009 está regulamentada a escolarização obrigatória no País para a população dos quatro aos 17 anos de idade, tendo sido o ano de 2016 a data limite para que essa exigência fosse cumprida pelos entes federativos (MINISTÉRIO DA EDUCAÇÃO, 2009).

No que se refere às(aos) docentes, o número de professoras(es) no Ensino Médio era de 519,6 mil em todo o Brasil, correspondendo a 23,6\% das(os) docentes da educação básica (MINISTÉRIO DA EDUCAÇÃO, 2017b). De acordo com o relatório do Tribunal de Contas da União (TCU) de 2014, havia nas redes estaduais de educação um déficit de cerca de 32.000 professoras(es) com formação em licenciatura para ministrar as 13 disciplinas ofertadas no Ensino Médio à época (BRASIL, 2014b).

No Gráfico 1 registra-se a adequação da formação docente no Ensino Médio por disciplina. Verifica-se que as disciplinas de Sociologia (72,9\%), Artes (58,9\%), Física (57,4\%) e Filosofia (55,8\%) estão sendo ministradas em um percentual altíssimo por professorasles) que não possuem a licenciatura adequada para ministrá-las. Entre esses(as) docentes estão bacharéis ou licenciados em áreas diferentes daquelas em que atuam, profissionais com formação superior que não contempla nenhuma das áreas das disciplinas e professoras(es) sem formação superior. 
Gráfico 1 - Adequação da Formação Docente ${ }^{7}$ do Ensino Médio por disciplina - Brasil - 2017

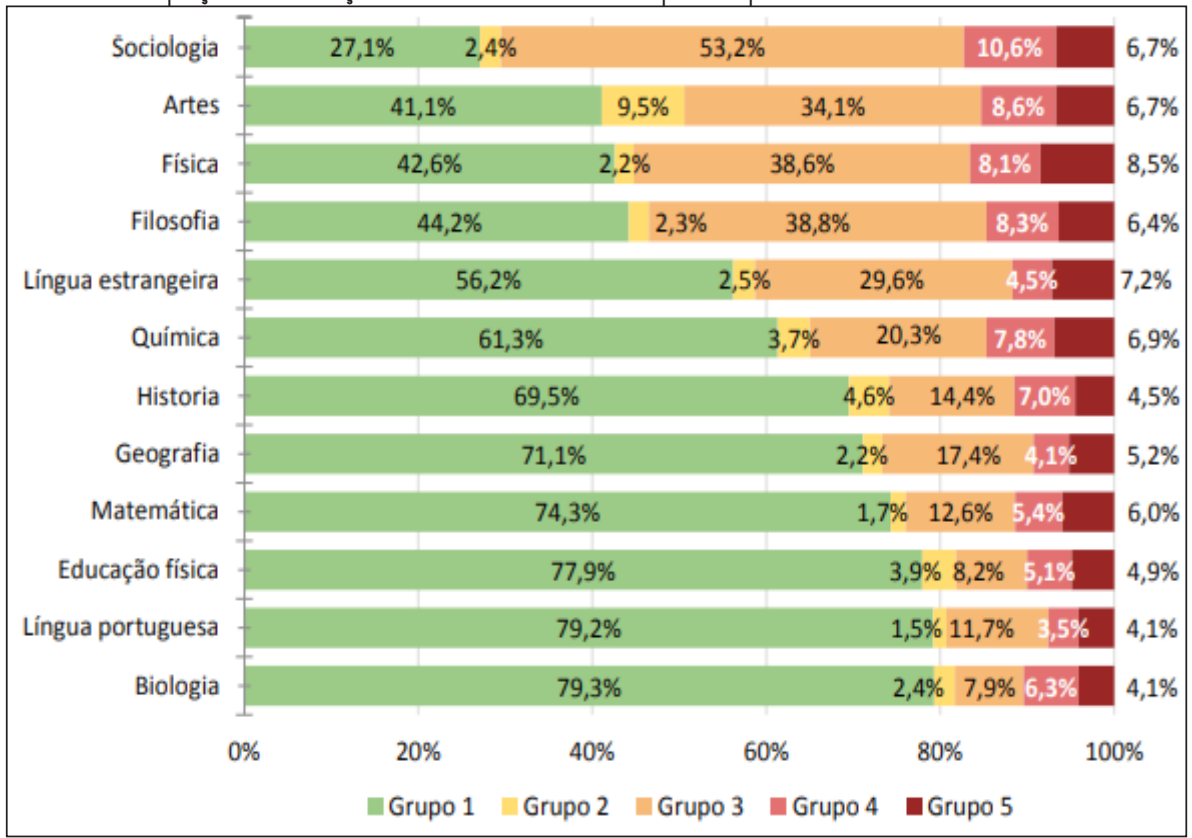

Fonte: Ministério da Educação (2018a).

Com relação às condições de infraestrutura dos estabelecimentos de Ensino Médio, o Censo Escolar de 2017 registrava entre os itens mais críticos o Laboratório de Ciências, presente em apenas 45,4\% das escolas brasileiras. Verifica-se na Tabela 1 que nas redes estaduais, onde se concentra o maior número de matrículas, o Laboratório de Ciências se apresenta somente em $39,2 \%$ das escolas; nas escolas federais estão em $81,3 \%$; e nas escolas privadas, em $58,3 \%$.

A Tabela 1 também revela que somente $43,5 \%$ das escolas estaduais possuem as dependências previstas no PNE (2014-2018) em sua meta 7, estratégia 7.18, ${ }^{8}$ enquanto a rede federal possui 76,6\%, e as escolas privadas, 52,4\% (MINISTÉRIO DA EDUCAÇÃO, 2017b). Chamam

\footnotetext{
${ }_{7} \quad$ "Grupo 1 - Percentual de disciplinas que são ministradas por professores com formação superior de licenciatura lou bacharelado com complementação pedagógica) na mesma área da disciplina que leciona; Grupo 2 - Percentual de disciplinas que são ministradas por professores com formação superior de bacharelado (sem complementação pedagógica) na mesma área da disciplina que leciona; Grupo 3 - Percentual de disciplinas que são ministradas por professores com formação superior de licenciatura (ou bacharelado com complementação pedagógica) em área diferente daquela que leciona; Grupo 4 - Percentual de disciplinas que são ministradas por professores com formação superior não considerada nas categorias; Grupo 5 - Percentual de disciplinas que são ministradas por professores sem formação superior."

8 "Meta 7 - estratégia 7.18) assegurar a todas as escolas públicas de educação básica o acesso a energia elétrica, abastecimento de água tratada, esgotamento sanitário e manejo dos residuos sólidos, garantir o acesso dos alunos a espaços para a prática esportiva, a bens culturais e artísticos e a equipamentos e laboratórios de ciências e, em cada edifício escolar, garantir a acessibilidade às pessoas com deficiência." (BRASIL, 2014a).
} 
a atenção as condições desiguais entre as escolas das redes públicas estaduais $(68,2 \%$ em relação às escolas privadas (29\%), a segunda em número de matrículas, e à rede federal, que participa com um percentual de $0,9 \%$ de escolas.

Tabela 1 - Recursos relacionados à infraestrutura disponivel nas escolas de Ensino Médio segundo dependência administrativa - Brasil 2017

\begin{tabular}{lrrrr}
\hline \multicolumn{5}{c}{ Dependência Administrativa } \\
\multicolumn{1}{c}{ Infraestrutura } & $\begin{array}{c}\text { Federal } \\
\text { (n=552) }\end{array}$ & $\begin{array}{c}\text { Estadual } \\
\text { (n=19.490) }\end{array}$ & $\begin{array}{c}\text { Municipal } \\
\text { (n=245) }\end{array}$ & $\begin{array}{c}\text { Privada } \\
\text { (n=8.271) }\end{array}$ \\
\hline Biblioteca ou sala de leitura & $97,8 \%$ & $85,9 \%$ & $80,8 \%$ & $92,5 \%$ \\
Biblioteca (dentro ou fora da escola) & $99,8 \%$ & $90,2 \%$ & $95,1 \%$ & $89,0 \%$ \\
Banheiro PNE & $92,9 \%$ & $59,5 \%$ & $53,9 \%$ & $67,0 \%$ \\
Dependências PNE & $76,6 \%$ & $43,5 \%$ & $37,6 \%$ & $52,4 \%$ \\
Laboratório de ciências & $81,3 \%$ & $39,2 \%$ & $28,2 \%$ & $58,3 \%$ \\
Laboratório de informática & $98,7 \%$ & $83,8 \%$ & $63,3 \%$ & $69,8 \%$ \\
Internet & $99,3 \%$ & $90,9 \%$ & $75,5 \%$ & $92,3 \%$ \\
Banda larga & $94,2 \%$ & $76,8 \%$ & $61,2 \%$ & $86,7 \%$ \\
Pátio (coberto ou descoberto) & $88,2 \%$ & $77,0 \%$ & $82,4 \%$ & $89,7 \%$ \\
Quadra de esportes (coberta ou descoberta) & $69,0 \%$ & $74,6 \%$ & $67,8 \%$ & $83,3 \%$ \\
\hline
\end{tabular}

Fonte: Ministério da Educação (2018a).

Desconsiderando o cenário esboçado, o Governo Temer apresentou a contrarreforma do Ensino Médio. As alterações propostas estavam voltadas para a reorganização dessa etapa de ensino, implantando uma nova estruturação curricular viabilizada por uma parte geral e uma parte flexível composta por cinco itinerários formativos; essa nova estruturação fomentou também a extensão da jornada escolar, reduziu as disciplinas obrigatórias para três - Português, Matemática e lnglês - e introduziu a modalidade de estudos e práticas em substituição às disciplinas de Sociologia, Filosofia, Artes e Educação Fisica.

A Lei n. 13.415/2017 manteve 800 horas/ano como carga horária mínima para essa etapa da educação básica, devendo ser ampliada progressivamente para 1.400 horas. Para a formação geral das(os) estudantes está prevista uma carga horária total de 1.800 horas, em que o currículo proposto deve estar de acordo com as normativas da Base Nacional Curricular Comum do Ensino Médio. A carga horária restante deve ser organizada em itinerários formativos. De acordo com Kuenzer (2017, p. 334), 
[...] a carga horária de componentes curriculares comuns corresponde a dois terços de um percurso de 3 anos com 800 horas por ano e a $60 \%$ de um percurso de 3 anos com 1.000 horas por ano; caso o percurso seja integral, com 1.400 horas por ano em 3 anos, o conteúdo comum corresponderá a $38 \%$ do total do curso, ou seja, pouco mais que um terço.

A organização da segunda parte do currículo apresenta as seguintes possibilidades de itinerários: Linguagem e suas Tecnologias; Matemática e suas Tecnologias; Ciências da Natureza e suas Tecnologias; Ciências Humanas e suas Tecnologias; Formação Técnica e Profissional. Esses percursos serão implantados de acordo com a disponibilidade orçamentária e de pessoal e das condições de infraestrutura das redes públicas. São as redes públicas, portanto, que decidirão o que ofertar. No entanto, as propagandas enganosas veiculadas pelo Governo Federal na ocasião da tramitação da MP levavam as(os) jovens a acreditarem que seriam eles(as) a escolher seus itinerários.

Uma dessas propagandas institucionais veiculadas nas redes abertas de televisão exibia jovens que anunciavam seus projetos de futuro: "Eu quero fazer jornalismo!", "Eu quero ser professora. É o que eu amo", “E eu, designer de games”, "Eu quero um curso técnico para já poder trabalhar". Por fim, a locução proclamava: "Com o novo Ensino Médio você tem mais liberdade para escolher o que estudar, de acordo com a sua vocação. É a liberdade que você queria para decidir o seu futuro". ${ }^{9}$ No entanto, a pretensa flexibilização do currículo, a partir de cincos percursos formativos, não será produto da escolha das(os) estudantes, como toda a publicidade institucional buscou construir em narrativas audiovisuais do protagonismo juvenil. A decisão de oferta está nas mãos dos sistemas de ensino, ao passo que para as(os) jovens as possibilidades de escolha serão diminutas, ou mesmo inexistentes.

Cabe destacar entre os itinerários aquele que prevê a formação técnica e profissional, pois, para sua implantação, prenunciaram-se a parceria público e privado, ${ }^{10}$ a contratação de profissionais com "notório saber", o reconhecimento de experiências do setor produtivo e a sua realização a distância, o que nos faz pressupor que poderá ser o itinerário mais ofertado no País. Tal proposta de formação é uma farsa improvisada de preparação para o mundo do trabalho que aprofunda o abismo ao acesso de uma formação escolar plena e digna.

A formação técnica e profissional proposta na Lei n. 13.415/2017 está em concordância com recomendações da Unesco (2003) e do Banco Mundial (2007), instituições

\footnotetext{
A peça publicitária permanece disponivel no canal oficial do Ministério da Educação no YouTube (COM 0 NOVO..., 2016).

10 A Lei n. 11.494/2007 (Fundeb) (BRASIL, 2007) foi alterada para permitir a contratação do setor privado a fim de ofertar esse itinerário.
} 
que propõem o desenvolvimento na educação secundária de estruturas flexíveis e opções variadas que ampliem os vínculos com o mundo do trabalho. Elas recomendam, ainda, a oferta da educação profissional em escolas especializadas e por intermédio de parceria entre os setores público e privado.

$\mathrm{Na}$ perspectiva dessas instituições, a ênfase do processo de aprendizado está colocada no desenvolvimento de competências e de habilidades individuais das(os) estudantes, que podem, entre outros aspectos, lhes ser úteis em termos de empregabilidade, considerando as crises estruturais do capitalismo e o desemprego na contemporaneidade (UNESCO, 2003; BANCO MUNDIAL, 2007). 0 modelo de empreendedorismo, defendido pelos organismos internacionais, está presente nessa contrarreforma e busca responsabilizar a(o) própria(o) jovem pela sua empregabilidade, reforçando os processos de invidualização e culpabilizando-as(os) pelos seus sucessos ou fracassos.

Como se pode verificar, trata-se de uma contrarreforma que produz uma redução na formação geral e uma fragmentação da formação das(os) estudantes em itinerários, o que reduz, quando não inviabiliza, as possibilidades de aprovação desses sujeitos em processos seletivos para continuidade dos estudos na educação superior (KUENZER, 2017). Nesse sentido, pode-se dizer que o Ensino Médio público está se restringindo a um instrumento voltado para formar as(os) estudantes para o mercado de trabalho, por meio de um ensino técnicoprofissionalizante precário, o que pode levar, também, a precários postos de trabalho (ARAUJO, 2019), quando estes estiverem disponiveis se se considerar o fenômeno do desemprego estrutural tão forte atualmente.

Com relação à política de expansão da jornada para o Ensino Médio, contida no texto da Lei n. 13.415/2017, hora alguma explicita a compreensão do que seja educação integral, tampouco faz qualquer referência a atividades para serem desenvolvidas nos tempos reservados a ela. A experiência de educação integral implica, segundo Arroyo (2012), mudar o nosso sistema escolar, que por tradição é desenvolvido por meio de grades curriculares, portanto rígido e historicamente segregador em relação às camadas populares. Implica, ainda, a organização e/ou expansão do espaço físico, na alteração da jornada de trabalho das(os) professoras(es) e outras(os) profissionais da educação, além de investimentos financeiros diferenciados, considerando as condições de infraestrutura e de pessoal existentes nas escolas públicas, a fim de garantir a qualidade necessária aos processos de mudança (MOLL, 2012).

A instituição da política de tempo integral para o Ensino Médio, no entanto, beneficia apenas 500 unidades escolares, cerca de 2,5\% das escolas do País. Está prevista a liberação de recursos para as escolas públicas dos estados e do DF, por meio de transferência anual e pelo prazo de 10 anos. Essa transferência deverá respeitar a disponibilidade orçamentária do Ministério da Educação, que deve ser definida pelo seu ministro (BRASIL, 2017a). 
A forma como está sendo implementada a jornada integral nas escolas públicas de Ensino Médio acaba por criar maior diferenciação entre elas, considerando não só o fato de englobar apenas 2,5\% dessas escolas, mas também por ter exigido determinada infraestrutura para inclusão das escolas estaduais no programa. Esse último aspecto levou a contemplar aquelas que já apresentam melhores condições físicas e materiais.

A proposta de ampliação progressiva da carga horária diária para 1.400 horas anuais, ou seja, sete horas diárias, desconsidera o enorme contingente de jovens trabalhadoras(es) que frequentam o ensino noturno e a Educação de Jovens e Adultos (EJA). Ademais, a contrarreforma despreza a escola noturna, grande responsável por abrigar a ampliação do Ensino Médio. Tal indiferença pode ser compreendida como um projeto de restringir a oferta do Ensino Médio noturno, dirigindo as matrículas para cursos supletivos, interditando o direito à educação às(aos) jovens das camadas populares (LEÃ0, 2018).

Pela descrição e pela análise do formato da contrarreforma do Ensino Médio apresentadas nesta seção, verifica-se a influência dos organismos internacionais, o aprofundamento dos processos de privatização da educação pública, a flexibilização como eixo estruturador dessa proposta e a perda de direitos. Esse quadro presente na contrarreforma do Ensino Médio exige a formação de indivíduos flexíveis que possam "[...] submeter-se ao novo, o que supõe, subjetividades disciplinadas que lidem adequadamente com a dinamicidade, a instabilidade, a fluidez." (KUENZER, 2017, p. 341).

Nessa perspectiva, as(os) estudantes do Ensino Médio público se tornam alvo, já que são lançados precocemente à escolha de itinerários de estudos, formados para o mercado de trabalho flexível e colocados como responsáveis diretos pela sua empregabilidade. Dessa maneira, a contrarreforma do Ensino Médio ignora as aspirações e lutas da juventude brasileira.

\section{AUSÊNCIA DE ESCUTA DOS SUJEITOS DA ESCOLA}

A partir da década de 1990, ocorreu um intenso processo de expansão do Ensino Médio com o aumento de vagas e matrículas nas escolas públicas brasileiras, gerando uma transformação significativa no perfil das(os) jovens alunas(os) que a ele chegavam. As escolas públicas passam a receber um contingente de alunas(os) cada vez mais heterogêneo, marcado pelo contexto de uma sociedade plural e desigual. Os conflitos e contradições de uma estrutura social excludente se tornam mais explícitos no interior da escola, interferindo nas trajetórias escolares e nos sentidos atribuídos à instituição (LEÃO; DAYRELL; REIS, 2011). 
Todos esses fatores foram desconsiderados pelos reformadores do Ensino Médio. 0s sujeitos da escola - jovens, professoras(es), comunidade escolar - foram absurdamente ignorados nessa construção política que afeta o cotidiano e o futuro da juventude brasileira, conforme salientamos na seção anterior. Assim, reforçamos o argumento de que a educação brasileira foi golpeada ao se desconsiderarem os saberes e as experiências docentes e estudantis/juvenis. Contudo, a posição das(os) jovens brasileiras(os) diante da proposta de contrarreforma mostrou-se caracterizada pela crítica e resistência.

Tal como Arroyo (2014), partimos da constatação de que cotidianamente o Ensino Médio está sendo repensado e ressignificado. Os sujeitos da ação educativa, docentes e jovens educandas(o)s reinventam os currículos da educação básica no chão das escolas, “.... nas salas de aula, na criatividade dos professores, no material didático que cada docente cria e incorpora." (ARROYO, 2014, p. 54). Reconhecer os coletivos docentes e juvenis, bem como suas experiências e anseios, deveria ser ponto de partida de qualquer proposta de reforma do Ensino Médio que privilegiasse a participação democrática.

No entanto, como acompanhamos, a contrarreforma do Ensino Médio levou em conta exclusivamente os interesses dos organismos internacionais, coincidentes com os interesses empresariais e as perspectivas privatistas da educação. Várias pesquisas indicam a ausência de reconhecimento e participação das(os) jovens como sujeitos reflexivos e ativos nos processos de construção das políticas públicas (SPOSITO, 2007), e o chamado "Novo Ensino Médio" não viabilizou espaços efetivos de participação das(os) jovens estudantes, professoras(es) e comunidades."

Apesar disso, a sociedade se mobilizou. Estudantes e professoras(es) lutaram em resistência contra as arbitrariedades do Estado. Em 2015, por exemplo, o movimento de ocupações das escolas paulistas protagonizado por estudantes secundaristas contra o "projeto de reorganização" do Governo do Estado de São Paulo la proposta consistia na realocação de centenas de milhares de estudantes e o fechamento de 94 escolas) despontou como uma contundente forma de luta (CAMPOS; MEDEIROS; RIBEIRO, 2016).

No final de 2016, diversas ocupações de escolas e universidades foram também organizadas em todos os estados brasileiros como resposta à medida provisória de reforma do Ensino Médio e à emenda constitucional do teto de gastos públicos. As(os) estudantes paranaenses ocuparam as primeiras escolas, e o movimento foi ampliado em todo o Brasil. A internet, as redes sociais digitais e os aplicativos de comunicação foram importantes suportes de construção e desenvolvimento das ações coletivas de ocupações escolares, reforçando a 
importância do ciberespaço e da cibercultura para as experiências juvenis contemporâneas. No ano de 2015, em São Paulo, “antes das primeiras ocupações serem deflagradas, já havia um amplo conjunto de posts, hashtags, abaixo-assinados e muitos comentários circulando intensamente nas redes sociais." (CORTI; CORROCHANO; SILVA, 2016, p. 1167). Com a larga ampliação das ocupações em 2016, a luta contra a reforma do Ensino Médio ecoou intensamente na arena on-line.

Nesse cenário, é curioso pontuar uma estratégia do Governo Temer de contratar canais do YouTube para realizar a comunicação institucional do Ministério da Educação para além das propagandas publicitárias veiculadas em redes de rádio e televisão. Dois canais muito populares entre o público jovem - "Você Sabia" e "Pyong Lee" latualmente com mais de 26 milhões e cinco milhões de inscritas(os), respectivamente) - postaram vídeos elogiando a reforma com aparente espontaneidade e sem aviso de que se tratava de materiais patrocinados pelo Governo. Os vídeos foram fortemente criticados e hoje não estão mais disponíveis nos mencionados canais do YouTube.

As ocupações, por sua vez, constituíram-se em um movimento protagonizado pelas(os) jovens estudantes e privilegiaram o debate democrático, a coordenação de comissões responsáveis pela organização cotidiana que envolvia questões relativas a limpeza, alimentação, segurança, desenvolvimento de atividades, mobilização, etc. As assembleias instituíram-se como espaço para debate e deliberações. Algumas pesquisas e produções audiovisuais destacam o protagonismo das jovens mulheres estudantes como ocupantes ativas e dedicadas ao combate aos estereótipos e desigualdades de gênero no cotidiano do movimento (CORTI; CORROCHANO; SILVA, 2016). ${ }^{12}$ Inúmeras ações foram ofertadas nas ocupações, como oficinas, rodas de conversas, aulas, palestras, apresentações culturais e debates. Muitas manifestações de apoio e solidariedade foram recebidas, apesar das ocupações também terem sido criticadas por parte das comunidades escolares. Além da doação de alimentos e itens de higiene pessoal, diversas atividades educativas, culturais e artísticas foram desenvolvidas por sujeitos da comunidade escolar, mães e pais, estudantes e professoras(es) de outras escolas (da educação básica) e do Ensino Superior.

Como veremos, o currículo como "território contestado" (SILVA, 1998) foi questionado pelos coletivos juvenis/estudantis que demandavam outro Ensino Médio em que o direito à diferença estivesse presente. As experiências educativas nas ocupações mostraram a demanda por aulas que tivessem significado para as(os) jovens. As identidades e relações raciais, de gênero e sexualidade, os sentidos da escola, a cultura escolar, o mundo do trabalho, o Estado, a gestão democrática, as culturas e expressividades juvenis, entre tantas outras

\footnotetext{
$12 \quad$ Lute como uma menina é um documentário de 2016, dirigido por Flávio Colombini e Beatriz Alonso, que apresenta o protagonismo das jovens mulheres secundaristas nas ocupações paulistas (LUTE..., 2016).
} 
temáticas e práticas estiveram presentes nas composições curriculares das ocupações. Logo, "as imagens oferecidas pelos jovens nas ocupações - atuando, discursando, cozinhando e limpando - contrastam com as imagens tradicionais de estudantes calados e enfileirados nas salas de aula." (CORTi; CORROCHANO; SILVA, 2016, p. 1171). As ocupações das(os) secundaristas reforçaram que há autorias e criatividades nas escolas, há indagações teóricas e práticas, há saberes e respostas (ARROYO, 2014).

Uma série de representações e estigmas recai sobre a juventude brasileira e reproduz imaginários sociais sobre essa fase da vida como um "vir a ser" e dos(as) jovens como "incompletos(as)", "hedonistas" e "irresponsáveis" (DAYRELL; CARRANO, 2014). Nessa compreensão pouco se apreende sobre os sujeitos reais que frequentam a escola, as múltiplas dimensões da sua experiência social, suas demandas e expectativas. No cotidiano escolar, há uma tendência em não reconhecer a(o) "jovem" existente nalo) "aluna(o)", e, assim, a pluralidade de modos de ser jovem e as condições raciais, de gênero, de sexualidade, econômicas e territoriais que configuram suas experiências se tornam pouco perceptíveis. 0 desconhecimento e a incompreensão das múltiplas condições juvenis e sua consideração nas práticas curriculares inviabilizam relações educativas significativas e reforçam a crise de legitimidade da escola.

Se para as(os) jovens, com seus sonhos e projetos de vida, a contrarreforma representa um aprofundamento das desigualdades escolares, para os(as) professores(as) que atuam no Ensino Médio a aprovação da lei subestima não somente as condições de trabalho e as condições estruturais das escolas, mas também nega a especificidade da docência nessa etapa da educação básica que requer uma política de formação inicial e continuada orientada pelos princípios das Diretrizes Curriculares Nacionais para o Ensino Médio (DCNEM). 0 exercício da docência nessa etapa da educação básica exige que o(a) professor(a) integre, na mediação pedagógica, os conhecimentos científicos e tecnológicos de sua área, as competências didático-pedagógicas, os saberes sobre a realidade do mundo do trabalho e a formação em pesquisa.

A despeito das ações e políticas que, orientadas pelas DCNEM, vinham se instituindo para o Ensino Médio entre 2009 e 2014, o projeto de lei paradoxalmente intitulado Novo Ensino Médio relegou a existência de um conjunto de mecanismos institucionais que ensejavam a reformulação dessa etapa do ensino de maneira articulada, reunindo os entes federados, as redes de ensino e as instituições públicas de Ensino Superior em consonância com os interesses da sociedade civil.

Duas dessas ações merecem destaque porque pressupunham a centralidade da escola e o protagonismo de gestores, docentes e estudantes para definir práticas e processos. A primeira delas, o Programa Ensino Médio Inovador (Proemi), instituído pela Portaria n. 971 , de 9 de outubro de 2009, demonstra que uma das justificativas mais alardeadas pelos 
contrarreformistas - a necessidade de mudança no currículo do Ensino Médio - vinha sendo objeto de uma incisiva atuação do Ministério da Educação. Com o Proemi, as escolas que aderissem ao Programa eram estimuladas a construir - a partir de suas realidades e das demandas juvenis - Propostas de Redesenhos Curriculares que se alinhassem aos projetos político-pedagógicos, contemplando as dimensões do trabalho, da ciência, da cultura e da tecnologia, bem como integrando os conhecimentos das diferentes áreas do conhecimento que compõem o currículo.

No intuito de apoiar e fortalecer os Sistemas de Ensino Estaduais e Distrital no desenvolvimento de propostas curriculares inovadoras nas escolas de Ensino Médio, - programa disponibilizaria apoio técnico e financeiro para que as escolas pudessem desenvolver ações pedagógicas que fossem gradativamente incorporadas ao currículo, na perspectiva de ampliar qualitativamente o tempo de permanência do(a) estudante na escola e de possibilitar a formação humana integral (MINISTÉRIO DA EDUCAÇÃO, 2009).

Articulado ao Proemi, o Ministério da Educação instituiu, pela Portaria n. 1.140, de 22 de novembro de 2013, o Pacto Nacional pelo Fortalecimento do Ensino Médio (PNEM), que fomentava ações coordenadas entre a União e os governos estaduais e distrital que elevassem o padrão de qualidade do Ensino Médio brasileiro. A formação continuada de professores(as) e coordenadores(as) pedagógicos(as) das escolas de Ensino Médio em todo o País foi uma das duas ações estabelecidas pelo PNEM, com a finalidade de iniciar um processo de rediscussão das práticas docentes à luz das diretrizes curriculares para a formação da juventude brasileira, restabelecendo a importância do ofício docente na formação humana integral de cada aluno. Ao configurar o papel da docência nessa etapa da educação básica, diante de tantos desafios e contradições, torna-se evidente a potência de uma política de formação continuada articulada à formação inicial passível de conferir a vez e a voz aos(às) professores(as) do Ensino Médio (MINISTÉRIO DA EDUCAÇÃO, 2013).

0 PNEM apresentou-se como uma perspectiva de formação continuada que buscava o reconhecimento das contradições acerca dos sentidos da escolarização, uma vez que elas estão impressas na prática pedagógica dos(as) professores(as), e quaisquer mudanças requerem o empenho de cada professor(a), amparado(a) por seus pares. Tal como preconizam suas diretrizes, o PNEM anunciava exequibilidade de novos desenhos curriculares gestados na escola, espaço significativo das práticas pedagógicas ao longo de todo o processo e trajeto educativo progressivo para o desenvolvimento de capacidades para a prática docente em situações e contextos reais.

Essas duas ações que se desenvolviam no momento de aprovação da Medida Provisória e a contrarreforma que se desenhou a seguir confirmam a ausência da escuta dos sujeitos da escola e o distanciamento das múltiplas e desiguais condições de vida juvenis contemporâneas. Hodiernamente, temos em curso um conjunto de medidas que altera significativamente a 
experiência escolar e os projetos de vida de mais de 10 milhões de jovens. A falta de legitimidade da contrarreforma é sublinhada por processos autoritários e arbitrários, visto que professoras(es) e jovens são concebidos como destinatários das políticas públicas, e não como atores com direito à participação na sua elaboração (LEÃ0, 2018). Autoritarismo e falta de diálogo com os sujeitos e as experiências no chão da escola também caracterizaram a construção das proposições curriculares e a Base Nacional Curricular Comum para o Ensino Médio.

\section{GOLPE NO CURRÍCULO}

Como foi discutido até aqui, tem-se em curso no País um conjunto de contrarreformas baseadas na privatização, o que Price (2014, p. 1622) nomeia de "cruzada anti educação (sic) pública." São projetos elitistas, antidemocráticos, que contrariam o entendimento de educação como um bem público comum e um direito a ser universalizado.

A grande promessa da contrarreforma do Ensino Médio, desde a MP 746, é a flexibilização curricular. Em suas inúmeras propagandas que enaltecem o “Novo Ensino Médio”, o Governo Temer tenta convencer que a medida modernizaria o currículo. Por meio dessa estratégia discursiva, divulga-se que o velho Ensino Médio estaria agonizando em razão do excesso de disciplinas e de sua rigidez. Isso é um argumento falacioso. A Lei de Diretrizes e Bases da Educação Nacional (LDBEN), Lei n. 9.394/1996, era, no texto anterior às mudanças impostas pela Lei n. 13.415/2017, bastante flexível e, exceção feita à Filosofia e Sociologia, não obrigava o ensino de $३$ disciplinas. Ela exigia apenas que se contemplassem obrigatoriamente certos "componentes curriculares" em uma organização livre do currículo nas escolas.

Nas palavras de Simões (2016, p. 3), "a imagem quase generalizada da imposição legal para o currículo do ensino médio é uma distorção da realidade das normas legais." Restringe-se, com isso, a análise e divulga-se que basta um novo currículo, único, padrão, obrigatório e centralizado a ser "aplicado" pelas(os) professoras(es) em todo o País, e assim - "Novo Ensino Médio" surgirá magicamente. Esse discurso que responsabiliza "o currículo pelas mazelas da educação, buscando mostrar suas insuficiências" tenta "interditar o próprio debate sobre os limites da escola em uma sociedade marcada pela desigualdade." (CURY; REIS; ZANARDI, 2018, p. 76).

Com isso, não se pretende, de modo algum, negar que o currículo escrito seja um instrumento bastante importante e que carrega consigo a potência de aprimorar significativamente os processos educativos de uma escola ou de um sistema de ensino. No entanto, as mazelas de que padece nosso Ensino Médio são bastante complexas e demandam investimentos muito mais amplos e consistentes do que apenas um currículo 
formal seria capaz de equacionar. Essa é uma discussão antiga e amplamente debatida por educadoras(es) do mundo todo. No Brasil, isso foi pauta de intenso debate especialmente por ocasião da elaboração dos Parâmetros Curriculares Nacionais (PCN), ainda nos anos 1990.

Diante desse debate antigo, questiona-se por que tanto investimento governamental justamente na elaboração de um currículo único para todo o território nacional, agora sob a legenda de Base Nacional Comum Curricular (BNCC)? Essa e inúmeras outras questões têm sido discutidas e analisadas por diversas(os) pesquisadoras(es) da área. Muitas hipóteses se anunciam. Neste artigo discute-se uma delas: a de que está em curso no País um golpe na educação e no currículo.

Há tempos, estudiosas(os) do campo curricular vêm argumentando que todo o currículo é uma seleção interessada. Os conteúdos e conhecimentos que o compõem passam por um longo processo em que determinados grupos conseguem fazer valer seus interesses. Em meio a intricadas relações de poder, determinados saberes são incluídos e outros excluídos do currículo. Ele é, portanto, o resultado desse processo de disputa. Por isso conclui-se que ele é um "território contestado" (SILVA, 1998).

Em decorrência dessa argumentação, questiona-se a elaboração de um currículo único, nacional e obrigatório. Ainda que esse debate traga uma ampla disputa interna no próprio campo educacional e curricular (BATISTA; LUGLI; RIBEIRO, 2017), registra-se a contundente oposição à BNCC, desde o início de sua elaboração, por parte da Associação Brasileira de Pesquisa e Pós-Graduação em Educação (ANPEd) e da Associação Brasileira de Currículo (ABdC), expressa em diversas moções e manifestos públicos (ASSOCIAÇÃO NACIONAL DE PÓSGRADUAÇÃO E PESQUISA EM EDUCAÇÃO, [201-], 2015). Posição essa também assumida neste artigo, ou seja, a de contestar a regulação imposta pela atual política de currículo em curso no Brasil, que estabelece conhecimentos restritos, selecionados de modo arbitrário, em um contexto de golpe de estado, atendendo a interesses de grupos privatistas.

Posições como essas se multiplicam em todo o País. Em decorrência disso, o Governo Federal precisou lançar mão de determinadas estratégias discursivas para minimizar as resistências e conseguir construir uma pretensa hegemonia em torno da necessidade da BNCC (CORTEZZI, 2018; MACED0, 2016). Uma dessas estratégias foi justamente afirmar que a BNCC, aprovada pelo Conselho Nacional de Educação (CNE) e homologada pelo Ministério da Educação, não é um currículo e vem investindo para convencer a sociedade desse fato.

A despeito dessa pretensa confusão conceitual, concordamos com Cury, Reis e Zanardi (2018, p. 67) de que "não é possivel negar a natureza curricular da BNCC simplesmente porque ela a rejeita." Ressalvamos, no entanto, que, embora a BNCC seja de fato um currículo prescrito e com ambição de unificar a distribuição do conhecimento escolar, em concordância agora com Macedo (2018, p. 29), ela "não esgotaria as possibilidades de ser do currículo." 
Essa ressalva baseia-se na compreensão de que todo e qualquer currículo oficial vai necessariamente passar por inúmeros processos de tradução cultural, de resistências e de recriações até sua efetiva prática no currículo em ação nas escolas, como discutiremos ainda nesta seção.

Outro grave retrocesso trazido pela BNCC consiste na opção pela prescrição detalhada de competências e habilidades. Esse equívoco restringe o trabalho formativo das escolas a aspectos utilitaristas, instrumentais e eficienticistas. Verificam-se nessa abordagem os problemas já duramente criticados há mais de 20 anos por ocasião dos PCNs (SLLVA, 2008; LOPES; MACED0, 2002), que agora regressam como um "empoeirado discurso" (SILVA, M. R., 2018, p. 1), uma estreita "concepção de formação humana marcada pela intenção de adequação à lógica do mercado e à adaptação à sociedade." (SILVA, M. R., 2018, p. १1).

Um currículo único, nacional, obrigatório, como a BNCC consiste, ainda, em um instrumento de controle e regulação social, tendo seu potencial nocivo intensificado pela articulação com a política de avaliações sistêmicas padronizadas, atualmente em curso no País. Com a seleção arbitrária de determinados conhecimentos para compor o currículo nacional, temos a exclusão de inúmeros outros. A justificativa de que essa seleção interessada consistiria em um suposto conjunto de saberes universais se afirma discursivamente em meio a desiguais relações de poder. São disputas acirradas pela definição daquilo que seria mínimo, básico e comum. Entendemos, no entanto, que o que se denomina universal é um conhecimento particular que é posicionado como tal pelas relações de poder (LOPES, 2010).

Esse processo de padronização, entre outros efeitos, atua na exclusão da diferença: "não são apenas os 'diferentes' que são privados de suas vidas para se enquadrarem na mesmidade universal, todos perdem o seu direito à diferença ao serem integrados na promessa do todos como um." (MACED0, 2015, p. 898). Essa exclusão pode ser duramente comprovada por meio da ausência da discussão de questões de gênero e de sexualidade na BNCC, temas tão demandados pelas(os) jovens estudantes do Ensino Médio nas experiências de ocupação, conforme mencionado na segunda seção deste artigo. É assustador constatar a eficiência com que grupos reacionários conseguiram se impor na disputa pela redação do documento (PARAÍSO, 2016; MACEDO, 2017).

Na versão da BNCC, aprovada em 2018, a diversidade de gênero e a sexualidade são mencionadas uma única vez entre as 154 páginas destinadas ao Ensino Médio. A supressão foi tão taxativa que as palavras "sexo" e "sexual" não são referidas em momento algum. Nem ao menos como adjetivo do conteúdo de "reprodução", o qual aparece uma única vez. Essa exclusão no currículo já duramente denunciada nas pesquisas do campo certamente representa um retrocesso sem precedentes. Um risco à construção de uma sociedade mais justa, sem preconceitos, discriminações, violências, violações e desigualdades. 
Aproveita-se para reiterar aqui nossa defesa da incorporação nos currículos das inúmeras questões que dizem respeito à diferença. Entre elas, destaca-se, no atual momento, aquelas relativas às dimensões das vivências de gênero e sexualidade. Elas merecem destaque especialmente por serem extremamente significativas nos modos como as(os) jovens conduzem suas vidas. Inúmeros estudos concluem sobre essa sua importância (cf. Andrade e Meyer (2014), Sales (2015, 2017), Aguiar (2017), Ferreira (2017) e Silva L. (2018)).

A juventude que habita as escolas de Ensino Médio vivencia de modo intenso os dilemas em torno de como se conduzir no que tange aos aspectos normativos de gênero e sexualidade. Entre os muitos assuntos, as(os) jovens questionam a regulação de como viver as feminilidades, as masculinidades, os prazeres, os afetos, os desejos, etc. Diante de tantas interrogações, a escola e o currículo são instâncias importantes para que a juventude conheça as diversas possibilidades de vivência das relações de gênero e sexualidade, bem como pesquise, discuta, reflita sobre elas e aprenda a conviver respeitosamente com cada uma delas.

Outro problema antigo que a BNCC retoma, em consonância com a Lei n. 13.415/2017, é a organização do currículo por áreas do conhecimento. Recupera, inclusive, a nomenclatura dos Parâmetros Curriculares Nacionais (PCN) (BRASIL, 1999): Linguagens e suas Tecnologias; Matemática e suas Tecnologias; Ciências da Natureza e suas Tecnologias; Ciências Humanas e Sociais Aplicadas. Essa implementação demandaria um conjunto de esforços formativos, no sentido de reorganizar a formação inicial e continuada de professoras(es), que ainda permanece prevalentemente disciplinar. Cria-se, dessa maneira, um impasse para que as redes de ensino e as próprias escolas equacionem professoras(es) formadas(os) por disciplina e um currículo que demande uma articulação por área. lsso exige toda uma política formativa e também tempos específicos de elaboração conjunta de planejamentos curriculares. Tudo isso demanda, no mínimo, consideráveis investimentos financeiros os quais não estão garantidos, considerando o congelamento do orçamento da educação quando se aprovou a Emenda Constitucional 95/2016.

Compondo o golpe do currículo, foram aprovadas em novembro de 2018 as novas Diretrizes Curriculares para o Ensino Médio (DCNEM), regulamentadas pela Resolução n. 3 da Câmara de Educação Básica (CEB) do CNE. Somados aos retrocessos impostos pela Lei n. $13.415 / 2017$ e pela BNCC, destacamos os inúmeros artigos que autorizam as parcerias com as instituições privadas; a fragmentação da educação por meio da certificação intermediária; a inviabilização do ensino noturno (por conta do seu excessivo aumento de carga horária); e a abertura à possibilidade de que $80 \%$ da carga horária da Educação de Jovens e Adultas(os) (EJA), 20\% do Ensino Médio e 30\% do ensino noturno sejam ofertadas a distância. Tais aspectos significam em seu conjunto um golpe que sequestra da juventude brasileira as chances de acessar o conhecimento escolar e, com isso, de formar-se criticamente e usufruir do direito à educação escolar. 
No entanto, cabe registrar, são limitadas as chances efetivas de um currículo nacional se impor hegemonicamente em uma perspectiva totalizante, por exemplo. Os processos tradutórios tornam impossível a pretensão de total controle e homogeneização curricular. A tradução opera em uma relação assimétrica, "construída em um espaço indefinido entre fidelidade e liberdade, continuidade e ruptura, coerência e transgressão." (CORAZZA, 2019, p. 4). Nesse sentido, é possível resistir.

0 golpe no currículo e todas as articulações voltadas para destruir a educação pública devem ser denunciados e combatidos. As formas de luta exigem energia, coragem, persistência e criatividade. Espera-se que as(os) educadoras(es) deste País, juntamente com a juventude, consigam resistir às imposições colocadas pela contrarreforma no Ensino Médio.

\section{CONCLUINDO...}

Este texto construiu reflexões sobre a realidade do Ensino Médio brasileiro e as propostas de sua reconfiguração a partir da Lei $n$. 13.415/17. As análises aqui empreendidas asseveram o caráter nefasto de um projeto deseducativo que ignora o cenário de infraestrutura precária das escolas públicas, das condições de trabalho das(os) professoras(es) e das experiências e subjetividades juvenis.

Apresenta, ainda, o paradoxo de diminuir as horas para formação geral e aumentar a extensão da jornada, sem nenhum projeto para o que é chamado de educação de tempo integral. Esse fato pode oportunizar maior disponibilização de atividades de cunho tecnicista e produtivista para a extensão da jornada, pois esse é o fio condutor do texto da Lei n. 13.425/2017.

Cabe lembrar que o desenho curricular proposto e discutido na última seção deste artigo foi estabelecido para fortalecer um conjunto de competências técnicas gerais e específicas que vêm sendo disseminadas pelos organismos internacionais e referendadas pelo Movimento Todos Pela Educação e seus parceiros.

Todo o processo de contrarreforma do Ensino Médio retira das(os) jovens o direito à educação, garantido no texto constitucional de 1988 e referendado na LDBEN (1996), e o substitui pelo que tem sido chamado de direito à aprendizagem, entendido como adquirir competências para o mundo do trabalho. Nesse sentido, o Banco Mundial (2007) afirma que o processo de escolarização não tem produzido esse tipo de aprendizagem e que é fundamental priorizá-la. Nessa perspectiva, as(os) jovens são submetidas(os) ao ensino técnico profissionalizante precário por meio da escola, sendo-lhes negado o direito ao acesso 
ao conhecimento necessário a essa etapa da educação básica, usurpando-se da escola a função de ofertá-lo.

Por tudo isso, unimo-nos para o enfrentamento necessário e urgente a essas políticas. Como educadoras comprometidas com o combate à desigualdade social e educacional, juntamo-nos às(aos) professoras(es) da educação básica e do Ensino Superior, aos movimentos sociais, às entidades científicas, aos sindicatos docentes e especialmente às juventudes deste País no combate à perversa contrarreforma do Ensino Médio. Denunciamos, neste artigo, suas falácias, seus riscos e seus potenciais destruidores das chances educacionais das(os) jovens brasileiras(os).

Esperamos, com isso, contribuir para o debate em torno dessa temática, oferecendo elementos que possam subsidiar a argumentação de todas(os) que, como nós, anseiam por uma escola justa. Nessa luta contra o golpe nos fortalecemos na certeza de que construiremos formas legitimas de enfrentamento, em um vigoroso tsunami da educação. Defendemos um presente respeitoso, repleto de oportunidades, rico em diversidades, com autênticas balbúrdias, rumo a um futuro no qual diferentes vidas sejam plenamente vivíveis.

\section{REFERÊNCIAS}

ANDRADE, S. S.; MEYER, D. E. Juventudes, moratória social e gênero: flutuações identitárias elm) histórias narradas. Educação em Revista, n. 1, p. 85-99, 2014. Edição Especial.

AGUIAR, J. S. Existo porque resisto: práticas de re-existência de jovens mulheres aprendizes frente às assimetrias de gênero. 2017. Dissertação (Mestrado em Educação) - Universidade Federal de Minas Gerais, Belo Horizonte, 2017.

ARAUJO, R. M. L. Ensino médio brasileiro. Dualidade, diferenciação escolar, reprodução das desigualdades. Uberlândia: Navegando Publicações, 2019.

ARROYO, M. G. 0 direito a tempos-espaços de um justo e digno viver. In: MOLL, J. et al. Caminhos da Educação Integral no Brasil - Direito a outros tempos e espaços educativos. Porto Alegre: Penso, 2012. p. 33-45.

ARROYO, M. G. Repensar o Ensino Médio: Por quê? In: DAYRELL, J.; CARRANO, P.; MAIA, C. L. Juventude e Ensino Médio: sujeitos e currículos em diálogo. Belo Horizonte: Editora UFMG, 2014. p. 57-73.

ASSOCIAÇÃO NACIONAL DE PÓS-GRADUAÇÃO E PESQUISA EM EDUCAÇÃO. ANPEd e a BNCC: luta, resistência e negação. Rio de Janeiro: Anped, [201-]. Disponivel em: http://www.anped.org.br/content/anped-e-bncc-luta-resistencia-e-negacao. Acesso em: 15 ago. 2019. 
ASSOCIAÇÃO NACIONAL DE PÓS-GRADUAÇÃO E PESQUISA EM EDUCAÇÃO. Exposição de motivos sobre a base nacional comum curricular. Rio de Janeiro: Anped, 29 nov. 2015. Disponivel em: http://www.anped.org.br/ news/exposicao-de-motivos-sobre-base-nacional-comum-curricular. Acesso em: 11 ago. 2019.

BANCO MUNDIAL. Ampliar oportunidades y construir competencias para los jóvenes - una agenda para la educación secundaria. [S. l]: Mayol Ediciones, 2007.

BATISTA, A. A. G.; LUGLI, R. S. G.; RIBEIRO, V. M. Centralização e padronização dos currículos: posições e tomadas de posição. Cadernos CENPEC, São Paulo, v. 7, n. 1, p. 75-104, jan./jul. 2017.

BRASIL. [Constituição (1988)]. Emenda constitucional n. 59 de 11 de novembro de 2009. Acrescenta § $3^{\circ}$ ao art. 76 do Ato das Disposições Constitucionais Transitórias para reduzir, anualmente, a partir do exercício de 2009, o percentual da Desvinculação das Receitas da União incidente sobre os recursos destinados à manutenção e desenvolvimento do ensino de que trata o art. 212 da Constituição Federal, [...] com a inserção neste dispositivo de inciso Vl. Diário Oficial da União, Braślia, DF, 12 nov. 2009.

BRASIL. Constituição. República Federativa do Brasil de 1988. Brasília, DF: Senado Federal, 5 out. 1988.

BRASIL. Lei n. 9.394, de 20 de dezembro de 1996. Estabelece as diretrizes e bases da educação nacional. Diário Oficial da União, Brasília, DF, 21 dez. 1996.

BRASIL. Lei n. 11.494, de 20 de junho de 2007. Regulamenta o fundo de manutenção e desenvolvimento da educação básica e de valorização dos profissionais da educação - Fundeb. Diário Oficial da União, Brasilia, DF, 21 jun. 2007.

BRASIL. Lei n. 13.415, de 16 de fevereiro de 2017. Altera as Leis n ${ }^{\circ}$ 9.394, de 20 de dezembro de 1996, que estabelece as diretrizes e bases da educação nacional, e 11.494, de 20 de junho 2007, [...] e institui a Política de Fomento à Implementação de Escolas de Ensino Médio em Tempo Integral. Diário Oficial da União, Brasília, DF, 17 fev. 2017.

BRASIL. Medida Provisória $n^{\circ}$ 746, de 22 de setembro de 2016. Institui a política de fomento à implementação de escolas de ensino médio em tempo integral, altera a Lei $n^{\circ}$ 9.394, de 20 de dezembro de 1996, [...] e dá outras providências. Diário Oficial da União, Brasília, DF, 22 set. 2016.

BRASIL. Parâmetros Curriculares Nacionais (PCN). Ensino Médio. Brasilia, DF: MEC/SETEC, 1999.

BRASIL. Plano Nacional de Educação. [S. l.: s. n.], 2014a. Disponivel em: http://pne.mec.gov.br/. Acesso em: 11 ago. 2019.

BRASIL. Tribunal de Contas da União. Relatório de atividades: 2014. Brasilia, DF: TCU, 2014b.

CAMPOS, A. M.; MEDEIROS, J., RIBEIRO, M. M. Escolas em luta. São Paulo: Veneta, 2016. 
COM 0 NOVO Ensino Médio, você tem mais liberdade para escolher o que estudar! [S. l.: s. n.], 2016. 1 vídeo (30 seg). Publicado pelo Canal Ministério da Educação. Disponivel em: youtube.com/ watch?v=kdERkL03eTs. Acesso em: १ ago. 2019.

CORAZZA, S. M. A-traduzir o arquivo da docência em aula: sonho didático e poesia curricular. Educação em Revista, Belo Horizonte, v. 35, 2019.

CORTEZZI, L. P. Argumentos favoráveis e contrários à BNCC: a construção discursiva de uma política curricular. 2018. Monografia (Graduação em Pedagogia) - Universidade Federal de Minas Gerais, Belo Horizonte, 2018.

CORTI, A. P. 0.; CORROCHANO, M. C.; SLLVA, J. A. Ocupar e resistir: a insurreição dos estudantes paulistas. Educação \& Sociedade, Campinas, v. 37, n. 137, p. 1159-1176, dez. 2016. D0I 10.1590/es010173302016167337.

CURY, C. R. J. A educação básica no Brasil. Educação \& Sociedade, Campinas, v. 23, n. 80, p. 168-200, set. 2002.

CURY, C. R. J. A nova lei de diretrizes e bases da educação nacional: uma reforma educacional? In: CURY, C.; HORTA, J. S.; BRITO, V. L. Medo à liberdade e compromisso democrático: LDB e Plano Nacional de Educação. São Paulo: Editora do Brasil, 1997. p. 91-136.

CURY, C. R. J.; REIS M.; ZANARDI, T. A. C. Base nacional curricular comum: dilemas e perspectivas. São Paulo: Cortez, 2018.

DAYRELL, J.; CARRANO, P. Juventude e ensino médio: quem é este aluno que chega à escola. In: DAYRELL, J.; CARRANO, P.; MAIA, C. Juventude e ensino médio: sujeitos e currículo em diálogo. Belo Horizonte: Editora UFMG, 2014. p. 102-133.

FERREIRA, A. G. \#Currículoemconexãocomacibercultura: a sociabilidade ciborgue e as juventudes no ensino médio. 2017. Dissertação (Mestrado em Educação) - Universidade Federal de Minas Gerais, Belo Horizonte, 2017.

FERRETI, C. J.; SLVA, M. R. Reforma do ensino médio no contexto da medida provisória n 7 746/2016: estado, currículo e disputas por hegemonia. Educação \& Sociedade, v. 38, n. 139, p. 385-404, jun. 2017.

KRAWCZYK, N.; FERRETTI, C. J. Flexibilizar para quê? Meias verdades da "reforma". Revista Retratos da Escola, v. 11, n. 20, p. 33-44, jan./jun. 2017.

KUENZER, A. Z. Trabalho e escola: a flexibilização do ensino médio no contexto do regime de acumulação flexível. Educação e Sociedade, v. 38, n. 139, p. 331-354, abr./jun. 2017.

IBGE. Pesquisa Nacional por Amostra de Domicílios: síntese de indicadores 2015. Rio de Janeiro: IBGE, $2016 a$. 
LEÃO, G.; DAYRELL, J. T.; REIS, J. B. Jovens olhares sobre a escola do ensino médio. Cadernos Cedes, v. 31, n. 84, p. 253-273, maio/ago. 2011.

LEÃO, G. 0 que os jovens podem esperar da reforma do Ensino Médio brasileiro? Educação em Revista, v. 34, 2018. DOI 10.1590/0102-4698177494.

LOPES, A. C. Currículo, política, cultura. In: SANTOS, L. et al. (org.). Convergências e tensões no campo da formação e do trabalho docente: currículo; ensino de educação física; ensino de geografia; ensino de história; escola, família e comunidade. 1. ed. Belo Horizonte: Autêntica, 2010. v. 1. p. 23-37.

LOPES, A. C.; MACEDO, E. Disciplinas e integração curricular. Rio de Janeiro: DP\&A, 2002.

LUTE como uma menina! [S. L.: s. n., 2016. 1 vídeo (76 min). Publicado no Canal Lute como uma meninal. Disponivel em: https://www.youtube.com/watch?v=80CUMGHm2oA. Acesso em: 11 ago. 2019.

MACEDO, E. "A Base é a base". E o currículo o que é? In: AGUIAR, M.; DOURADO, L. F. (org.). A BNCC na contramão do PNE 2014-2024: avaliação e perspectivas. Recife: ANPAE, 2018. p. 28-33.

MACEDO, E. As demandas conservadoras do movimento escola sem partido e a Base Nacional Curricular Comum. Educação \& Sociedade, v. 38, n. 139, p. 507-524, abr./jun. 2017.

MACEDO, E. Base Nacional Comum para Currículos: direitos de aprendizagem e desenvolvimento para quem? Educação \& Sociedade, v. 36, n. 133, p. 891-908, dez. 2015.

MACEDO, E. Base Nacional Curricular Comum: a falsa oposição entre conhecimento para fazer algo e conhecimento em si. Educação em Revista, v. 32, n. 2, p. 45-68, jun. 2016.

MINISTÉRIO DA EDUCAÇÃO. Censo escolar 2017. Notas estatísticas. Brasilia, DF: MEC: INEP, jan. 2018a.

MINISTÉRIO DA EDUCAÇÃO. Pacto Nacional pelo Fortalecimento do Ensino Médio: formação de professores do ensino médio: documento orientador preliminar. Brasília, DF, MEC: SEB, 2013.

MINISTÉRIO DA EDUCAÇÃO. Programa Ensino Médio Inovador. Documento orientador. Brasília, DF: MEC: SEB, set. 2009.

MOLL, J. Introdução. In: MOLL, J. et al. Caminhos da educação integral no Brasil. Direito a outros tempos e espaços educativos. Porto Alegre: Penso, 2012. p. 27-30.

OCDE. Education today: the OECD perspective. Paris: OECD Publishing, 2009.

PARAíSO, M. A. A ciranda do currículo com gênero, poder e resistência. Currículo sem Fronteiras, v. 16, n. 3, p. 388-415, set./dez. 2016.

PARTIDO DO MOVIMENTO DEMOCRÁTICO BRASILEIRO. Uma ponte para o futuro. Brasilia, DF: Fundação Ulysses Guimarães, 2015. 
PERONI, V. Reformas educacionais de hoje: as implicações para a democracia. Revista Retratos da Escola, v. 11, n. 21, p. 415-432, jul./dez. 2017.

POCHMANN, M. Estado e capitalismo no Brasil: a inflexão atual no padrão das políticas públicas do ciclo político da nova república. Educação e Sociedade, v. 38, n. 139, p. 309-330, abr./jun. 2017.

PRICE, T. A. Comum para quem? Revista e-Curriculum, São Paulo, v. 12, n. 3 p. 1614- 1633, out./dez. 2014. Disponivel em: http://revistas.pucsp.br/index.php/curriculum. Acesso em: 11 ago. 2019.

SALES, S. R. A ética e a estética da existência juvenil em duas lições curriculares do ensino médio: jogos de verdade sobre sexualidade e gravidez. In: MORGADO, J. C. et al. (org.). Currículo, internacionalização, cosmopolitismo: desafios contemporâneos em contextos luso-afro-brasileiros. Santo Tirso, Portugal: De Facto Editores, 2015. v. 1. p. 133-142.

SALES, S. R. Algumas lições curriculares sobre a estética da existência juvenil: disputas discursivas em torno da sexualidade e gravidez no ensino médio. In: MACEDO, E.; RANIERY, T. (org.). Currículo, sexualidade e ação docente. Petrópolis: DP et Alli, 2017. p. 75-90.

SILVA, L. Currículo da nudez: relações de poder-saber na produção de sexualidade e gênero nas práticas ciberculturais de nude selfie. 2018. Dissertação (Mestrado em Educação) - Universidade Federal de Minas Gerais, Belo Horizonte, 2018.

SILVA, M. R. A BNCC da reforma do repensar o ensino médio: o resgate de um empoeirado discurso. Educação em Revista, Belo Horizonte, v. 34, 2018.

SILVA, M. R. Currículo e competências: a formação administrada. São Paulo: Cortez, 2008.

SILVA, T. T. Currículo e identidade social: território contestado. In: SLVA, T. T. Alienígenas na sala de aula. 2. ed. Petrópolis: Vozes, 1998.

SIMÕES, C. A. Vozes dissonantes na reforma do ensino médio. Rio de Janeiro: Associação Nacional de Pós-Graduação e Pesquisa em Educação, 2016.

SPOSITO, M. (coord.) Espaços públicos e tempos juvenis: um estudo de ações do poder público em cidades de regiões metropolitanas brasileiras. São Paulo: Global, 2007.

UNESCO. 0 ensino médio no século XXI: desafios, tendências e prioridades. Brasília, DF, 2003. (Cadernos UNESCO. Série Educação, 9).

Endereço para correspondência: Avenida Presidente Antônio Carlos, 6627, Pampulha, Belo Horizonte, Minas Gerais, Brasil; driduarte58@gmail.com

Roteiro, Joaçaba, U. 45, p. 1-26, jan./dez. 2020 | e22528 |E-ISSN 2177-6059 
